\title{
Microstructure and Orientation Evolution of the Sn Phase as a Function of Position in Ball Grid Arrays in Sn-Ag-Cu Solder Joints
}

\author{
TAE-KYU LEE ${ }^{1,3}$ KUO-CHUAN LIU, ${ }^{1}$ and THOMAS R. BIELER ${ }^{2}$ \\ 1.-Component Quality and Technology Group, Cisco Systems, Inc., San Jose, CA 95134, USA. \\ 2.-Michigan State University, East Lansing, MI, USA. 3.-e-mail: Taeklee@cisco.com
}

The microstructure evolution of $\mathrm{Sn}-\mathrm{Ag}-\mathrm{Cu}$ solder joints during aging and thermal cycling is studied, with a focus on the Sn grain orientation in plastic ball grid array (PBGA) packages. Thermally cycled PBGA packages with a full array of 196 solder joints were examined after being subjected to various preconditions. Each PBGA package was polished to obtain plan-view crosssections of each solder joint. Solder joints were characterized using both polarized optical microscopy and orientation imaging microscopy (OIM). The observations reveal that the distribution of single and multigrain Sn microstructure as a function of position in the package is dependent on the sample's preconditions and thermal cycle history. Based on distribution maps from polarized optical microscopy observation, thermal aging has a relatively small impact on the overall fraction of single-grained solder joints. Thermal cycling, however, can cause many single-grained joints to transform into multigrained solder joints. The dependence of the grain structure distribution on different preconditions and evolution of the grain structures during thermal cycling are discussed.

Key words: Lead-free solder, Sn grain orientation, polarized image, microstructure, orientation image microscopy (OIM)

\section{INTRODUCTION}

Solder joints composed of $\mathrm{Sn}-\mathrm{Pb}$ alloys are considered to be homogeneous and deform in a relatively uniform manner. Unlike $\mathrm{Sn}-\mathrm{Pb}$ solder joints, lead-free solder alloys have strongly anisotropic thermal expansion and plastic deformation characteristics, resulting in different mechanical properties. ${ }^{1,2}$ Solder joints with different crystal orientations will have significantly different tensile, compressive, and shear characteristics, giving each lead-free solder joint in a given package unique mechanical properties.

As shown in Fig. 1 each lead-free solder joint has its own unique characteristics. A $4 \times 4$ joint sample

(Received March 16, 2009; accepted June 9, 2009;

published online July 1, 2009) with SAC305 solder alloy BGA balls with an electrolytic $\mathrm{Ni} / \mathrm{Au}$ surface finish was put under shear deformation until reaching its ultimate tensile strength (UTS). Before shear deformation, one side of the 16-joint sample was polished to reveal the cross-section of four of the solder joints, showing the deformation characteristics after shear deformation. Figure 1a-c are scanning electron microscopy (SEM) images of three different joints after shear deformation at a displacement rate of 0.01 $\mathrm{mm} / \mathrm{min}$. Deformation striation bands are observed near the package side in the joint. The striations in Fig. 1a are more horizontal than in Fig. 1b. Polarized-light images in Fig. 1d and e show that both solder joints are single-grain oriented solder joints. In contrast, Fig. $1 \mathrm{c}$ and $\mathrm{f}$ shows multigrain orientation structure with a different set of deformation striation bands. Based on these three solder joint examples, it is clear that deformation characteris- 

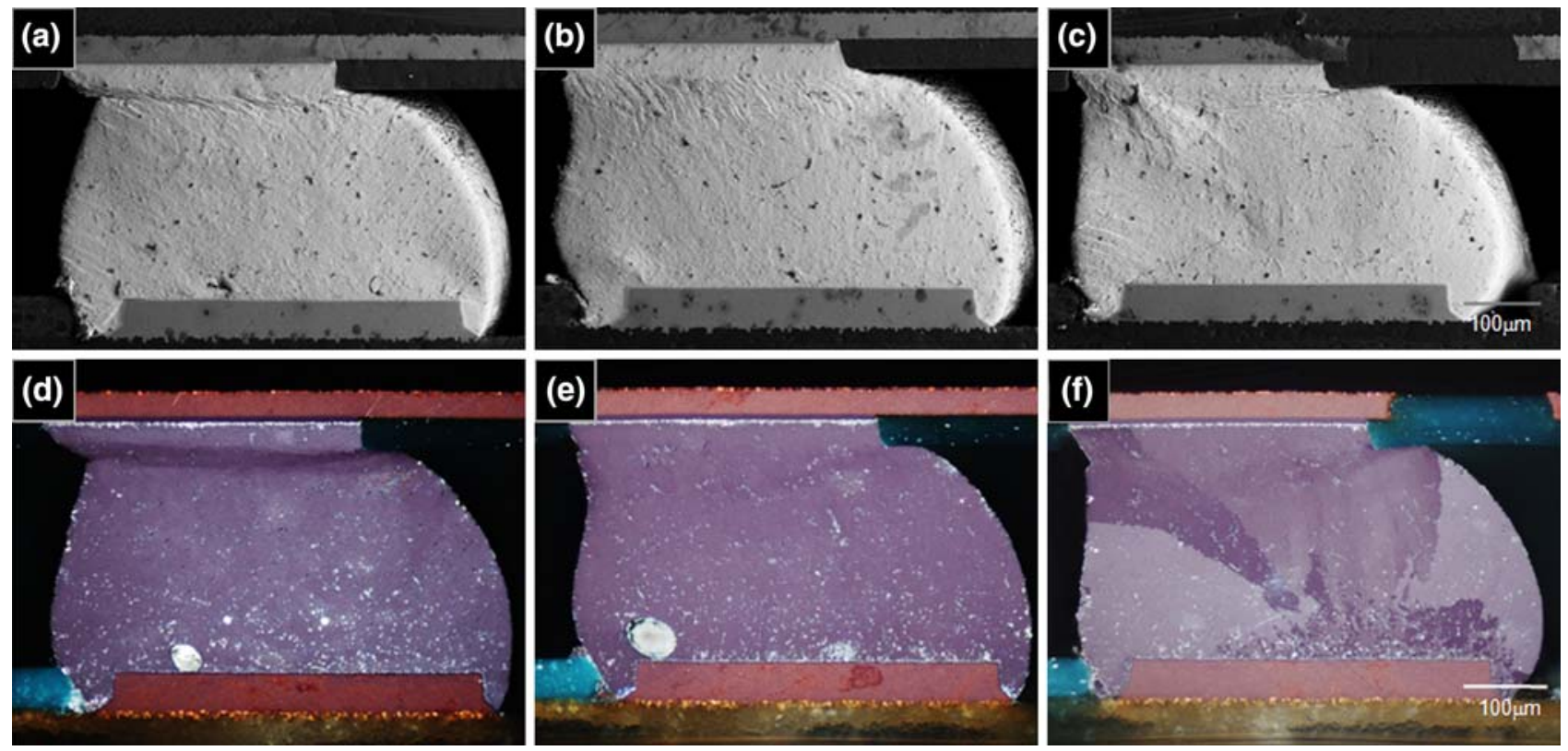

Fig. 1. (a-c) SEM images showing the microstructure of shear-deformed SAC305 solder joints and (d-f) polarized-light micrographs taken after shear deformation with a $0.01 \mathrm{~mm} / \mathrm{min}$ displacement rate.

tics vary even between single-grained Sn solder joints, and the strain differs in multigrained joints according to the arrangement of crystal orientations and grain boundaries. Detailed analysis of this phenomenon can be found in other publications. ${ }^{3}$

The Sn microstructure in solder joints has been studied in depth using orientation imaging microscopy (OIM) by Bieler and colleagues. ${ }^{4}$ Borgesen and colleagues recently published a detailed examination of solder joint cracking in a BGA test vehicle. ${ }^{5}$ The analyses in these publications demonstrated that fracture occurring after approximately 2500 thermal cycles between temperatures of $-40^{\circ} \mathrm{C}$ and $125^{\circ} \mathrm{C}$ is highly correlated with the dominant crystal orientation present in a solder joint. Many active research efforts aim to understand the general deformation mechanisms of solder joints. ${ }^{6-11}$ However, given the large difference in character between various solder joints, it is becoming more important to understand the distribution of individual grain orientations (and the consequent deformation mechanisms) and the impact of this distribution on the package as a whole. Packages can house hundreds of solder joints, each with a different stress-strain state based on package type, die size, etc.; a macroscopic view of the distribution of likely deformation mechanisms is needed.

In this paper, we focus on the overall distribution of single- and multigrained structures in order to investigate patterns in the solder joint grain structure present before and after thermal cycling. Both polarized-light microscopy and OIM are used to study the solder joint microstructure.

\section{EXPERIMENTAL PROCEDURES}

As shown in Fig. 2, samples consisted of a $15 \times 15 \mathrm{~mm}$ plastic ball grid array (PBGA) with a $14 \times 14$ full array of solder joints $(600 \mu \mathrm{m}$ in diameter) with $1.0 \mathrm{~mm}$ pitch between each solder joint. The composition of the solder balls used in this study is $\mathrm{Sn}-3.0 \mathrm{Ag}-0.5 \mathrm{Cu}$ (wt.\%) (SAC305). The PBGAs have a $5 \mathrm{~mm} \times 5 \mathrm{~mm}$ silicon die attached, and the package-side substrates have an electrolytic $\mathrm{NiAu}$ surface finish. Assembled parts are attached to a 2.4-mm-thick high- $T_{\mathrm{g}}$ FR4 printed circuit board with organic surface preservative (OSP) surface finish. Sn-3.0Ag-0.5Cu (wt.\%) (SAC305) solder paste was used for the reflow, and a typical peak temperature of $240^{\circ} \mathrm{C}$ with $60 \mathrm{~s}$ above the liquidus temperature reflow, was used for board assembly.

To study the effect of aging conditions, we subjected samples to an aging temperature of either $100^{\circ} \mathrm{C}$ or $150^{\circ} \mathrm{C}$, with a holding time ranging between $500 \mathrm{~h}$ and $1000 \mathrm{~h}$, in ambient air. For thermal cycling, we subjected samples to a $0^{\circ} \mathrm{C}$ to $100^{\circ} \mathrm{C}$ thermal cycle, with a ramp rate of $10^{\circ} \mathrm{C} / \mathrm{min}$ and a 10 min dwell time. During thermal cycling, samples were continuously monitored. For the sake of simplicity, results in this paper are based on samples after 0,1400 and 2500 cycles. The most accurate way to observe the grain orientation of each preconditioned sample is to look at a sideview cross-section. However, analyzing crosssections of all 14 rows is a tedious and inefficient process. As an alternative, a $z$-axis cross-section (bottom-view sample preparation) is used for 


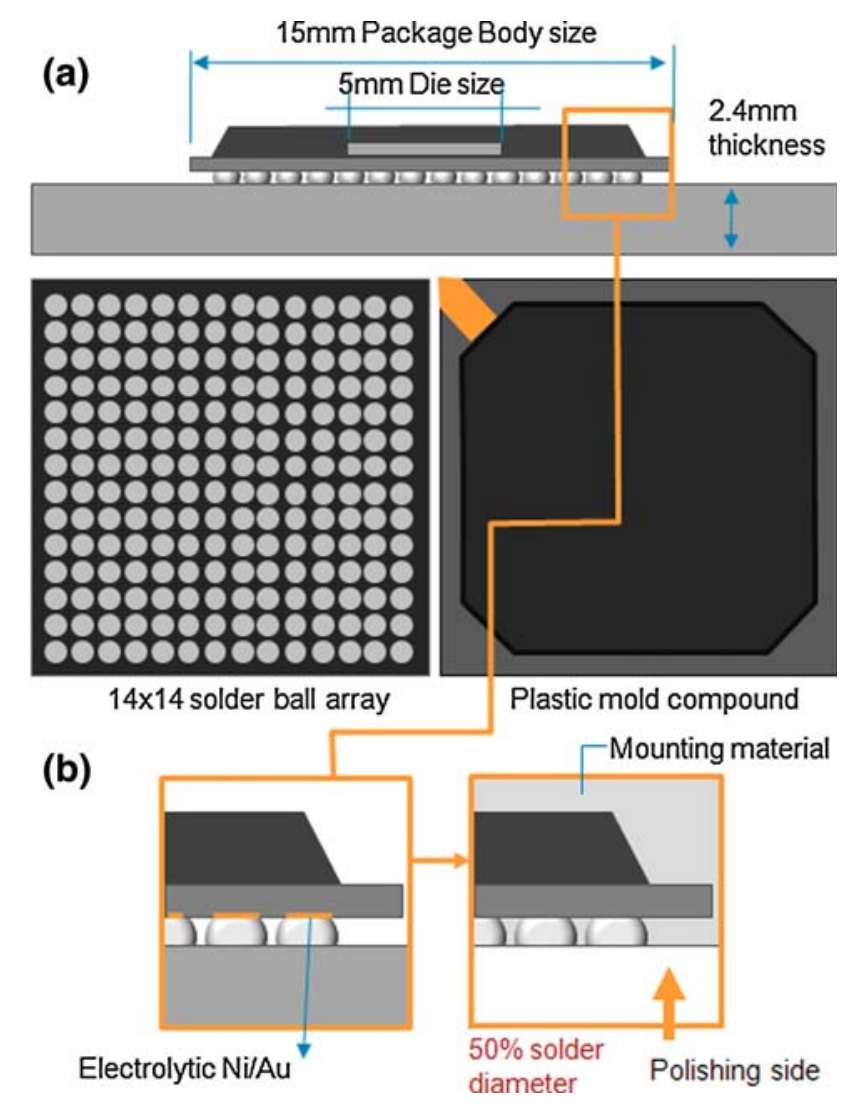

Fig. 2. Sample configuration schematics: (a) plastic ball grid array and (b) after polishing.

analysis. As shown in Fig. 2b, the mounted samples are polished from the printed circuit board (PCB) side to the solder joint. The $z$-axis crosssection is taken at $50 \%$ of each solder joint's height. Given the fact that the solder joint is very sensitive to sample preparation, the step-by-step sample mounting and polishing process was closely monitored. Previous sample preparation confirmed that the sample microstructure has not been altered during the sample preparation process and leads to good polarized light optical observations. A $z$-axis cross-section for each preconditioned PBGA sample was made and polished, and images of each individual solder joint were taken in high-resolution format for subsequent analysis. To measure the hardness, a micro Knoop hardness test was performed on cross-section joint samples. Five joints for each condition were tested using a load of $25 \mathrm{~g}$. Each joint was measured at four different test points, beginning from the package-side bulk solder and continuing to the board-side bulk solder. The average values for each location are given.

\section{RESULTS AND DISCUSSION}

Figure 3 shows the individual polarized light images of each solder joint arranged in their array positions after being subjected to different preconditions. Figure 3a shows the microstructure directly after board assembly, Fig. 3b after an aging period of $500 \mathrm{~h}$ at $100^{\circ} \mathrm{C}$, and Fig. $3 \mathrm{c}$ after an aging period of $1000 \mathrm{~h}$ at $150^{\circ} \mathrm{C}$. Each set of images shows a combination of single- and multigrained structures. From Fig. 3a-c, it is not easy to identify the dominant grain orientation structure distribution. Figure $3 \mathrm{~d}-\mathrm{f}$ shows the arrays after thermal cycling from $0^{\circ} \mathrm{C}$ to $100^{\circ} \mathrm{C}$ for 2500 cycles. It is difficult to see the difference in the overall distribution without a systematic approach. A relatively simple approach to reveal patterns in the grain structure involves categorizing each solder joint based on its polarized image. As shown in Table I, each solder joint was assigned to one of five categories: (1) single grain structure, (2) nearly two grain structures (mainly a single grain with a small fraction of a second grain orientation structure), (3) two grain structures, (4) nearly three grain orientation structures (two strong grain orientations with an additional small fraction of a different grain orientation structure), and (5) three grain orientations (either a clear beachball structure or more than three grains).

Figures 4 and 5 show the categorized grain structure distribution for selected joints before and after thermal cycling for the three different aging conditions in Fig. 3. As shown in Fig. 4, each array has a mixture of single- and multigrained solder joints. The distribution of single-grained solder joints in Fig. 5 was extracted from Fig. 4, where the unaged, as-assembled array samples and the thermally aged samples show a majority of singlegrained solder joints. The number of these singlegrained solder joints decreased after thermal cycling (Fig. $5 \mathrm{~d}-\mathrm{f}$ ). The sample thermally cycled after aging at $150^{\circ} \mathrm{C}$ showed the greatest reduction in single-grained joints. This trend is clearly seen in Fig. 6, where the percentage of single-grained structure solder joints is plotted against each precondition.

As shown in Fig. 6, the fraction of single-grained joints decreased right after the board assembly by $\sim 16 \%$. Prior to assembly, the sample is a freestanding PBGA sample, just after ball attachment. A possible driving force for this change is the build-up of internal stress during reflow, or doubling the interface area. Typically, during hightemperature reflow, the package experiences thermal expansion and elongation and has a tendency to warp, introducing additional internal stresses during the assembly process. The cooling, followed by the exposure to a high peak temperature, results in internal stresses in the solder joints that could later trigger the growth of a minority twin orientation during heating or cooling. Alternatively, additional interfacial area could also increase the number of multi-crystal solidification events. This process results in a lower fraction of single-grained joints.

When we compare the unaged, as-assembled samples with the samples aged at $100^{\circ} \mathrm{C}$ and $150^{\circ} \mathrm{C}$, 


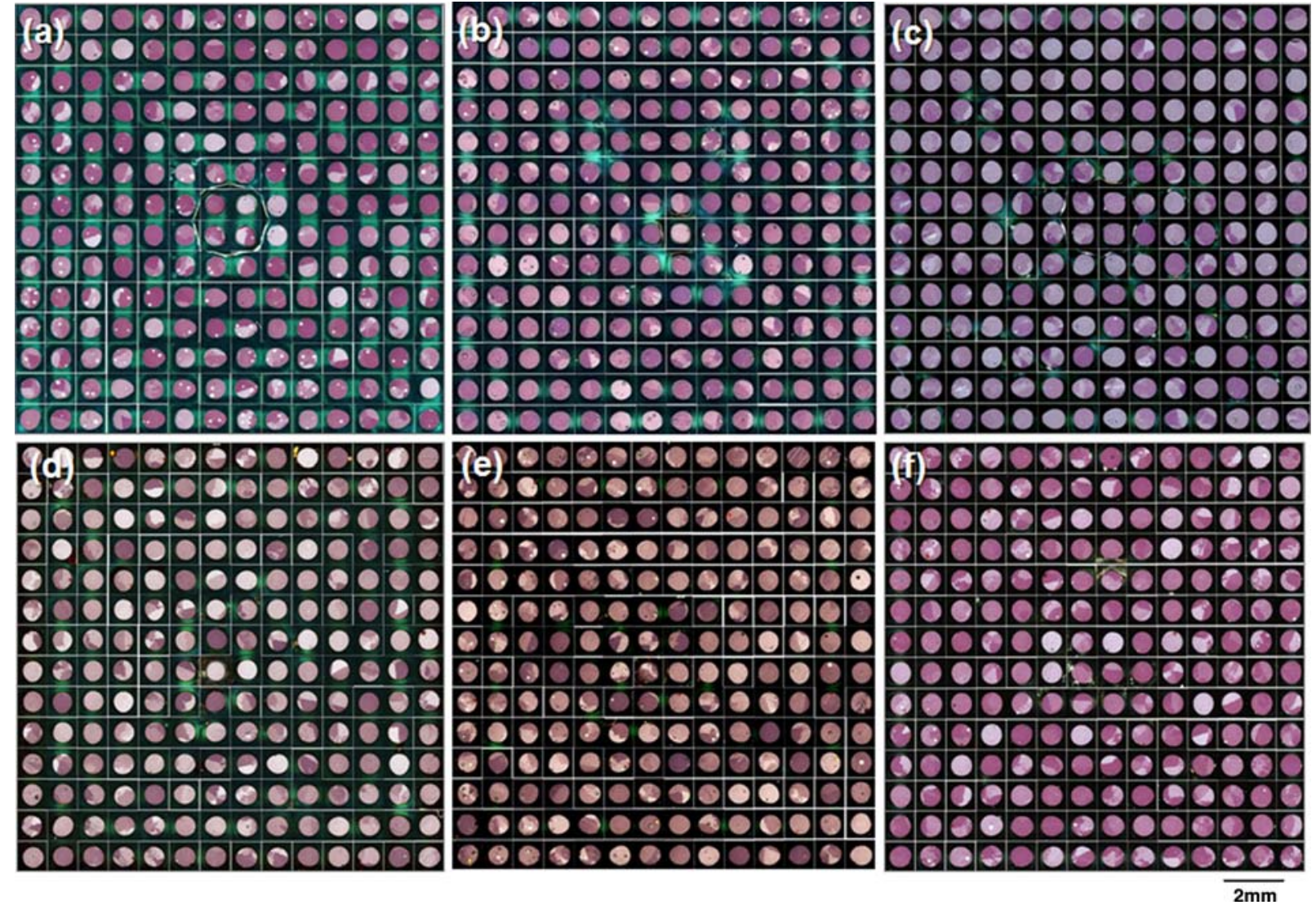

Fig. 3. Selected polarized images of PBGA samples: (a) unaged, as-assembled, (b) aged at $100^{\circ} \mathrm{C}$ for $500 \mathrm{~h}$, (c) aged at $150^{\circ} \mathrm{C}$ for $1000 \mathrm{~h}$, (d) unaged sample after thermally cycling for 2500 cycles, (e) aged at $100^{\circ} \mathrm{C}$ for $1000 \mathrm{~h}$ and thermally cycled for $2500 \mathrm{cycles}$, and (f) aged at $150^{\circ} \mathrm{C}$ for $1000 \mathrm{~h}$ and thermally cycled for 2500 cycles.

Table I. Grain Structure Categories

\begin{tabular}{|l|l|l|}
\hline Image & \multicolumn{1}{|c|}{ Category/type } & Indicator \\
\hline & $\begin{array}{l}\text { Single Grain structure } \\
\text { Solder joints with a single grain } \\
\text { under the polarized filter }\end{array}$ & $\begin{array}{l}\text { Near single grain structure } \\
\text { Solder joints with a second grain } \\
\text { orientation occupies less than } 20 \% \\
\text { of the joint area }\end{array}$ \\
\hline & $\begin{array}{l}\text { Two grain structure } \\
\text { Solder joints with two grain } \\
\text { orientation }\end{array}$ & \\
\hline & $\begin{array}{l}\text { Near three grain structure } \\
\text { Solder joints with two dominant } \\
\text { grain orientations and a minor third } \\
\text { orientation }\end{array}$ & \\
\hline & $\begin{array}{l}\text { Three grain structure } \\
\text { Solder joints with a clear beach ball } \\
\text { structure or more than three grain } \\
\text { orientations }\end{array}$ & \\
\hline & & \\
\hline
\end{tabular}

the percentage of single-grain oriented solder joints relatively remained unchanged by a small $8 \%$ reduction (as-assembled, 100-t1-TC0 and 150-t2TC0 in Fig. 6). Thermal aging subjects the samples to a relatively static condition, so the lack of a difference with aging make sense. On the other hand, the distribution of single-grained solder joints continuously decreases after thermal cycling. For the unaged sample, the fraction of single-grained joints drops from $49 \%$ to $37 \%$ after 1400 thermal cycles, and continues to drop to $30 \%$ after 2500 cycles. The same trend is seen for the samples aged at $100^{\circ} \mathrm{C}$ and $150^{\circ} \mathrm{C}$, with the reduction being more drastic in samples aged at $150^{\circ} \mathrm{C}$ than $100^{\circ} \mathrm{C}$. When we divided the overall area into more detailed subareas based on the silicon die location, the distribution of single-grained joints under the die area and outside the die area is summarized in Fig. 7. The fraction of single-grained joints decreases continuously with increasing number of thermal cycles. However, when the joints under the die were considered separately, the result shows that the sample aged at $100^{\circ} \mathrm{C}$ showed a different distribution than the sample aged at $150^{\circ} \mathrm{C}$. There is not a large difference between the distributions of the single-grained solder joints located directly under the die, compared with the solder joints located 

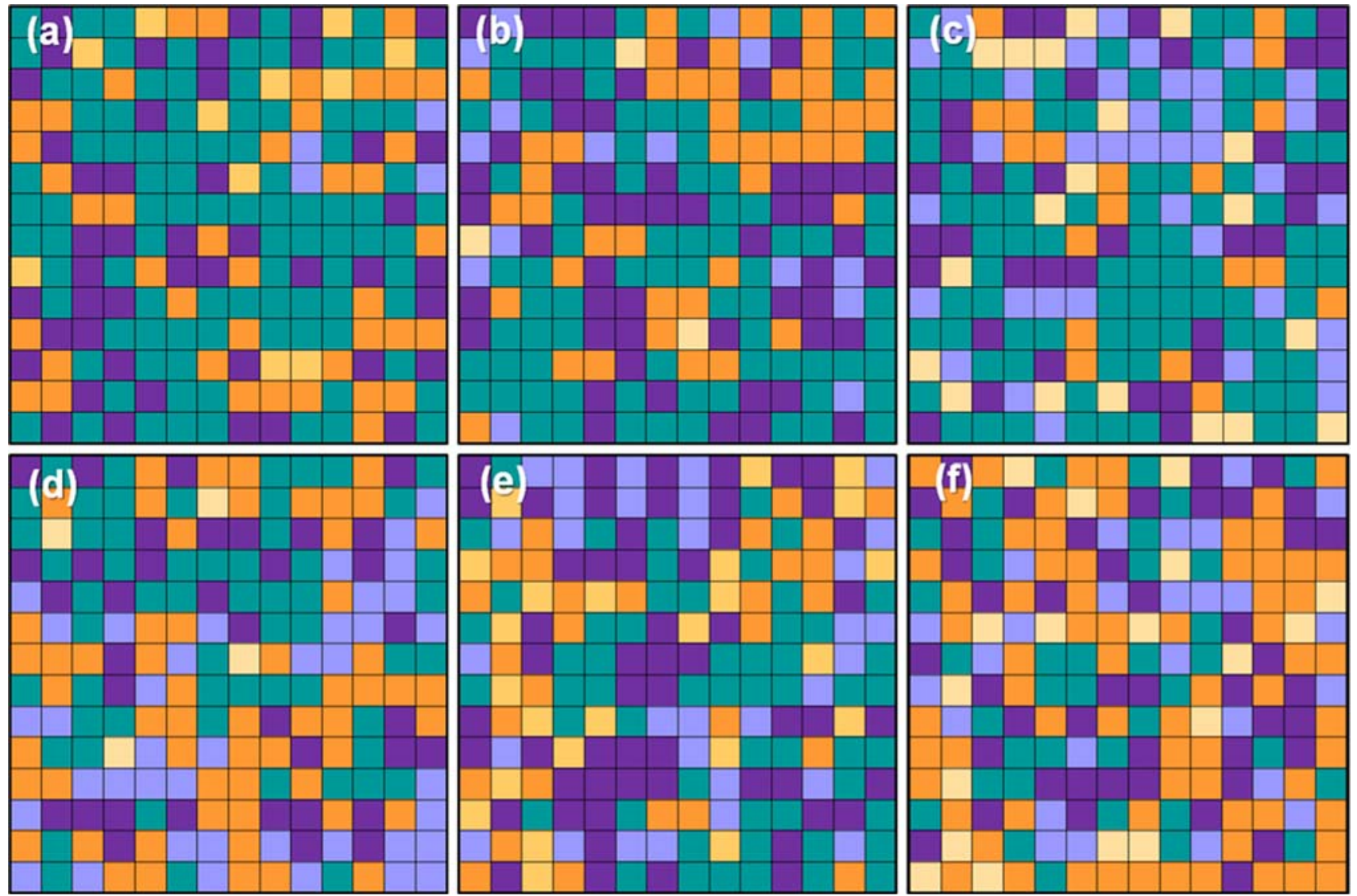

Fig. 4. Grain structure distribution map: (a) unaged, as assembled, (b) aged at $100^{\circ} \mathrm{C}$ for $500 \mathrm{~h}$, (c) aged at $150^{\circ} \mathrm{C}$ for $1000 \mathrm{~h}$, (d) unaged sample after thermal cycling for 2500 cycles, (e) aged at $100^{\circ} \mathrm{C}$ for $1000 \mathrm{~h}$ and thermally cycled for 2500 cycles, and (f) aged at $150^{\circ} \mathrm{C}$ for $1000 \mathrm{~h}$ and thermally cycled for 2500 cycles.

under the die edge shadow area, but the samples aged at $150^{\circ} \mathrm{C}$ show an immediate drop in the number of single-grained joints directly under the die area while the $100^{\circ} \mathrm{C}$ samples show a constant single-grained solder joint distribution after thermal cycling. We do not have enough data points to back up the statistics to confirm this trend, but because the area under the die in this package is relatively small and the substrate is relatively thick, it is expected that there is minimal mismatch in the coefficients of thermal expansion (CTE) during thermal cycling. Thus, the stress distribution at the die edge shadow area for both unaged and aged samples may be relatively similar. This suggest that the difference in the distribution of single-grained joints between unaged samples and those aged at $100^{\circ} \mathrm{C}$ or $150^{\circ} \mathrm{C}$ may be due to the differences in the bulk microstructure.

The decrease in the fraction of single-grained joints may be related to the accumulation and coarsening of precipitates within the solder. Figure 8 shows SEM images revealing the microstructure of the package side and board side. A relatively thick intermetallic layer is observed after aging, a common result of aging for a long time at high temperature. In addition to this change at the interface, the bulk area shows fewer and larger precipitates. SEM images of the samples after thermal cycling are shown in Fig. 8g-i for each condition. The images show a greater extent of precipitate coarsening and accumulation compared with the aged samples without thermal cycling for each condition. The precipitates in the aged sample (consisting predominately of $\mathrm{Ag}_{3} \mathrm{Sn}$ intermetallic particles) coarsen and are less effective in pinning the Sn subgrain boundaries between dendrite arms. The unpinned, low-angle grain boundaries coalesce, leading to larger low-angle boundaries with larger crystallographic misorientations within the Sn grains, ultimately resulting in a softer material. In the case where this process leads to the formation of grain boundaries with a $7^{\circ}$ misorientation, sliding processes are allowed. ${ }^{12}$ Microhardness data, shown in Fig. 9, indicates that the overall hardness of the joint material decreases after thermal aging. The hardness measurements were made in four different areas on a cross-sectioned package for each precondition, starting at the top (package side) and 

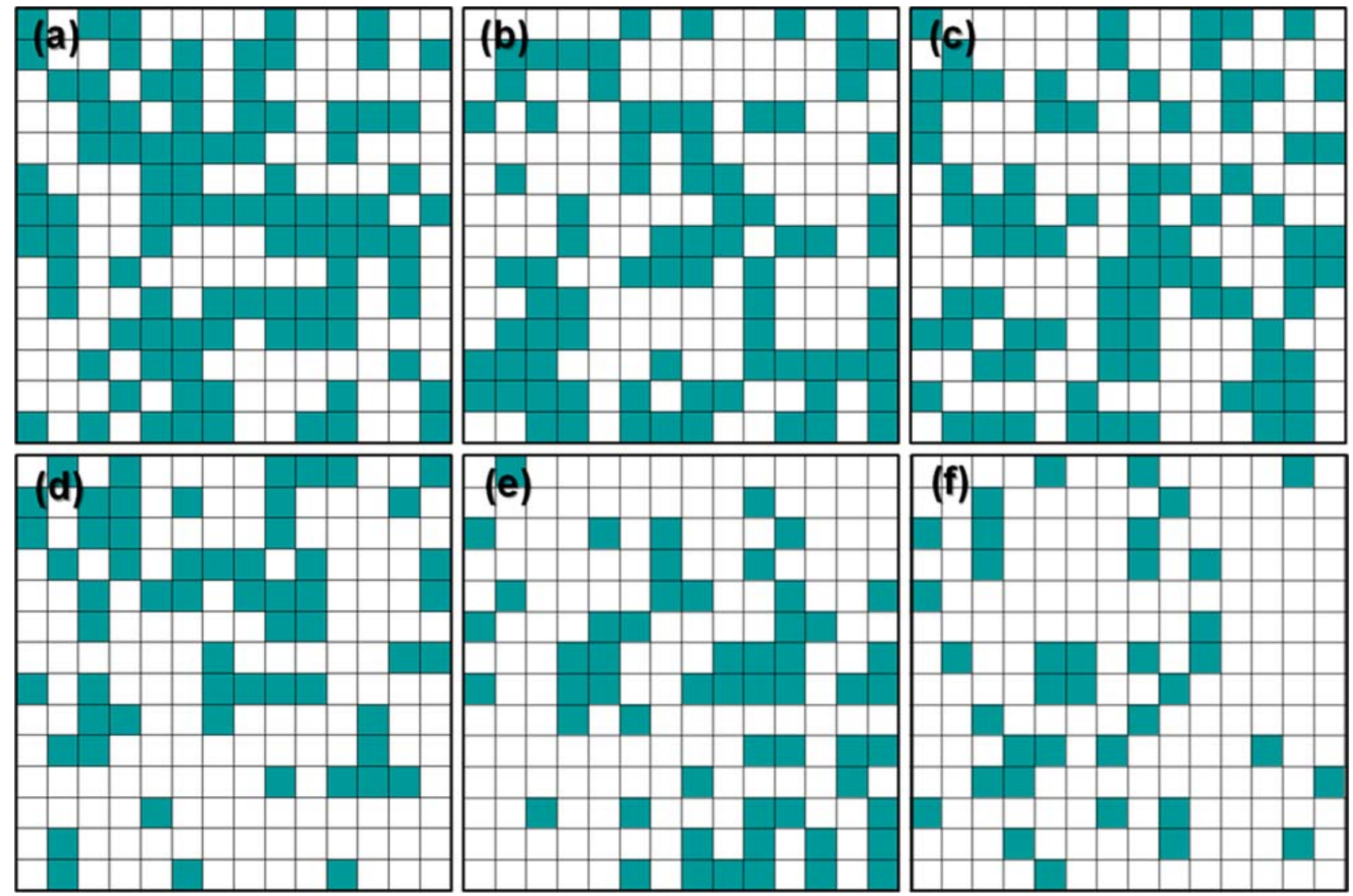

Fig. 5. Single-grained structure distribution map: (a) unaged, as-assembled, (b) aged at $100^{\circ} \mathrm{C}$ for $500 \mathrm{~h}$, (c) aged at $150^{\circ} \mathrm{C}$ for $1000 \mathrm{~h}$, (d) unaged sample after thermal cycling for 2500 cycles, (e) aged at $100^{\circ} \mathrm{C}$ for $1000 \mathrm{~h}$ and thermally cycled for 2500 cycles, and (f) aged at $150^{\circ} \mathrm{C}$ for $1000 \mathrm{~h}$ and thermally cycled for 2500 cycles.

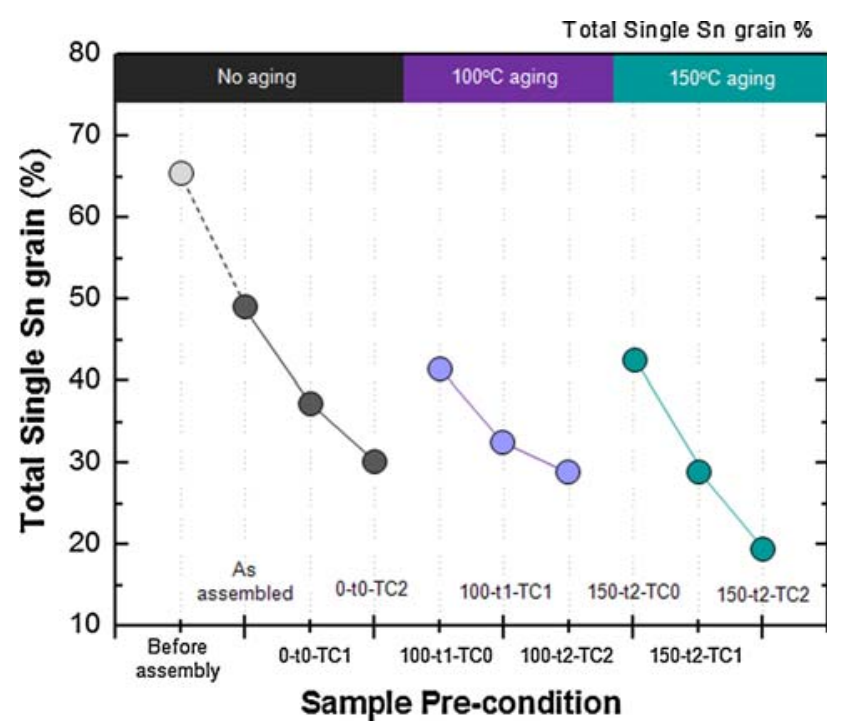

Fig. 6. Total single-grained orientation joint number percentage for each precondition. Specimen names indicate precondition, e.g., $\mathrm{PL}-100-\mathrm{t} 1-\mathrm{TC} 1$ indicates plan-view section aged at $100^{\circ} \mathrm{C}$ for $500 \mathrm{~h}$ and thermally cycled 1400 times $(\mathrm{t} 0=$ unaged, $\mathrm{t} 1=500 \mathrm{~h}, \mathrm{t} 2=1000 \mathrm{~h}$, TC1 $=1400$ cycles, TC2 $=2500$ cycles $)$.

continuing to the bottom (board side) inside the bulk solder. From the hardness data, we suspect that the coarsening precipitates allowed for an increase in grain boundary mobility. More mobile grain boundaries could serve to facilitate the transformation of single-grained structures to multigrained structures. A possible mechanism for growing a minority orientation is the incremental recrystallization and/or grain growth driven by the release of elastic strain energy. This is discussed in another publication, ${ }^{9}$ in which the growth of a minority orientation was shown to reduce the elastic strain energy that results from thermal cycling.

Optical microscopy with polarized light is a simple technique that immediately reveals the microstructure of Sn in solder joints, being especially useful for Sn-based solder. When polarized-light micrographs are compared with an OIM map, shown in Fig. 10, it is clear that not all solder balls have the same microstructure under the two imaging techniques (compare Figs. 3f and 10, which are the same package). A particular example of a solder ball with a different grain structure revealed by the different techniques is shown in Fig. 11. The polarized image shows several grain boundaries that become more or less visible during rotation of the specimen under polarized light from $0^{\circ}$ to $90^{\circ}$. Thus, a particular polarized-light micrograph may not provide the complete and detailed grain structure. A particular OIM map may not fully reveal the 


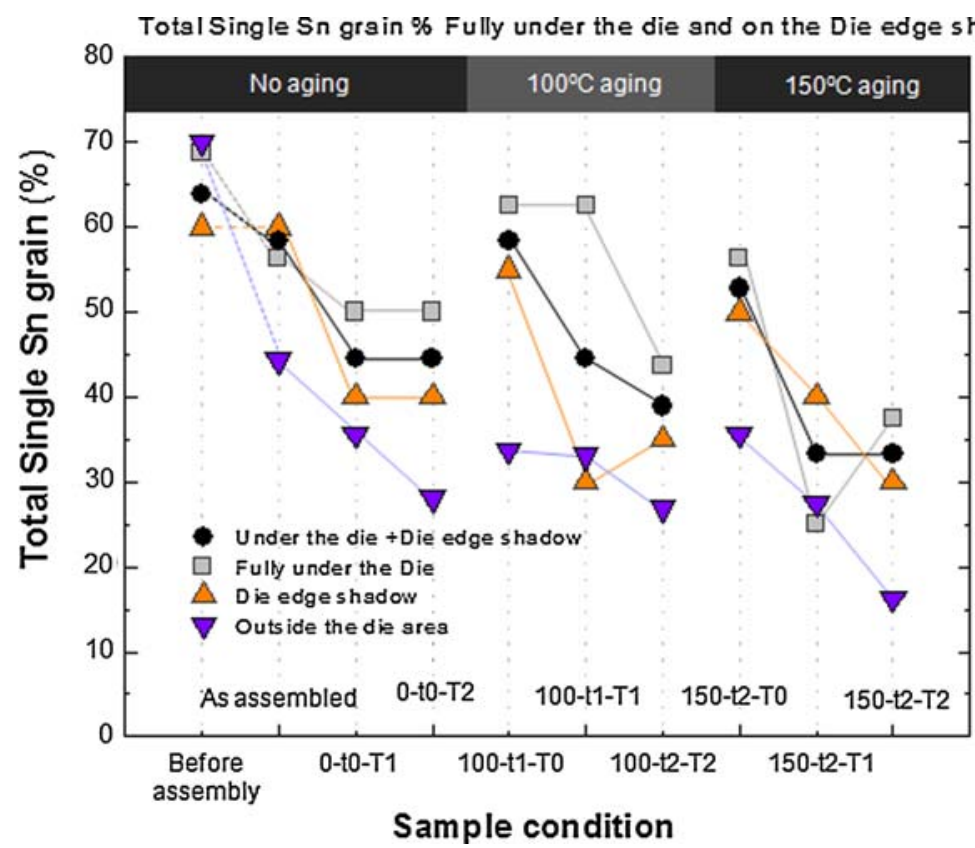

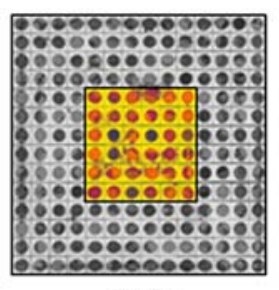

Under

the Die + Die edge

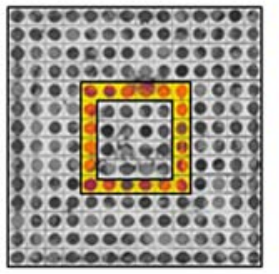

Die edge

shadow

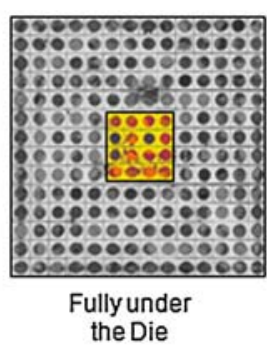

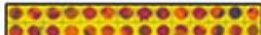

ㅂ.

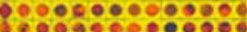

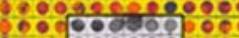
600000 300900000 000000 $8: 400005000$ 03050000 00000000000

Outside

the die

Fig. 7. Fraction of single-grained joints under the die area and outside the die area for each precondition.
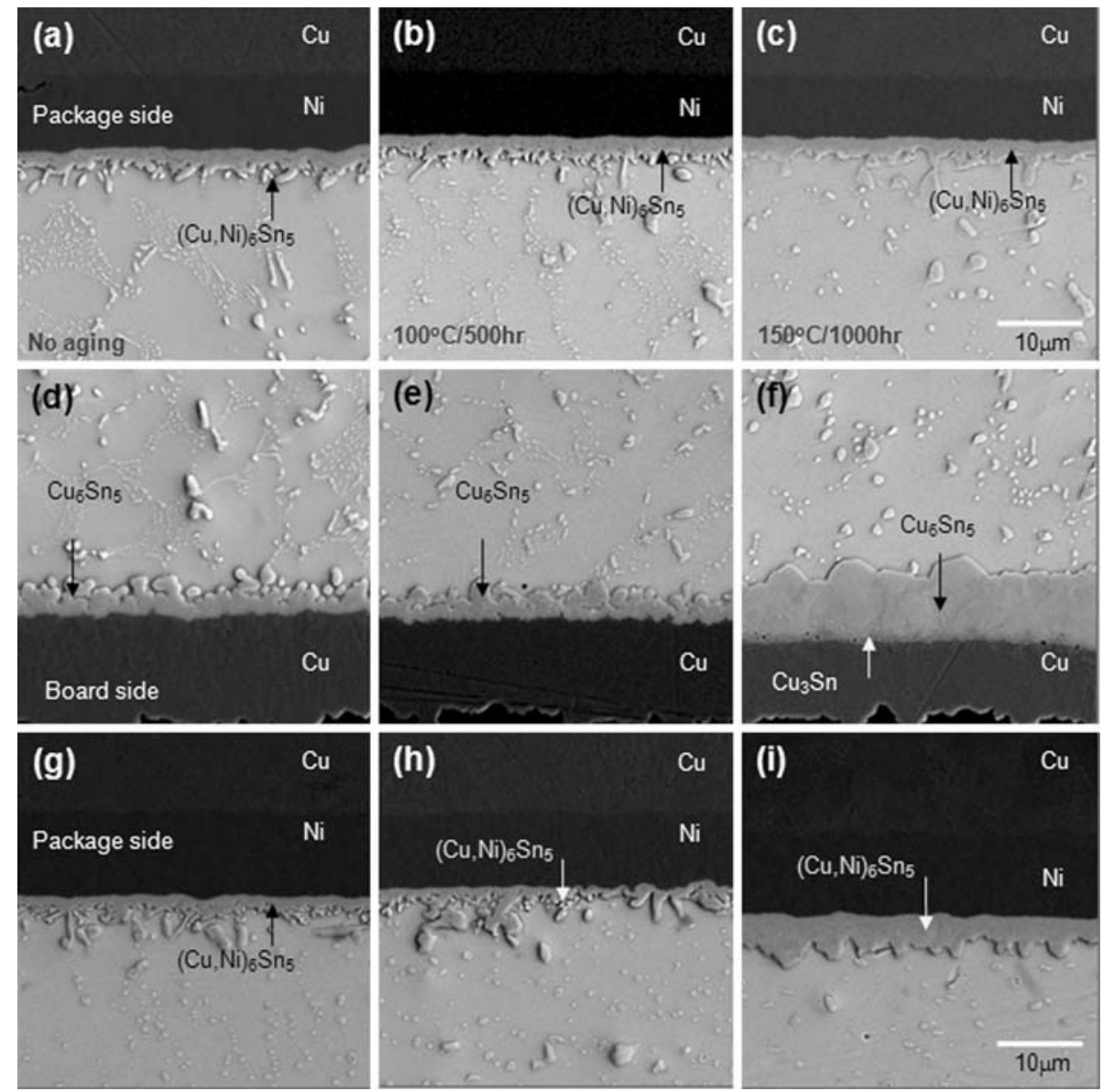

Fig. 8. SEM micrographs of the solder joints: $(a-c)$ and $(g-i)$ package side, $(d-f)$ board side. $(a, d)$ As-assembled and unaged, (b, e) aged at $100^{\circ} \mathrm{C}$ for $500 \mathrm{~h},(\mathrm{c}, \mathrm{f})$ aged at $150^{\circ} \mathrm{C}$ for $1000 \mathrm{~h}$, (g) unaged and then thermally cycled, (h) aged at $100^{\circ} \mathrm{C}$ for $500 \mathrm{~h}$ and thermally cycled, and (i) aged at $150^{\circ} \mathrm{C}$ for $1000 \mathrm{~h}$ and thermally cycled for 2500 cycles. 
complete grain structure either, as illustrated by joint D13, which appears to be a single crystal upon first glance of an OIM map. There are many ways to plot an OIM data set that allow for the extraction of

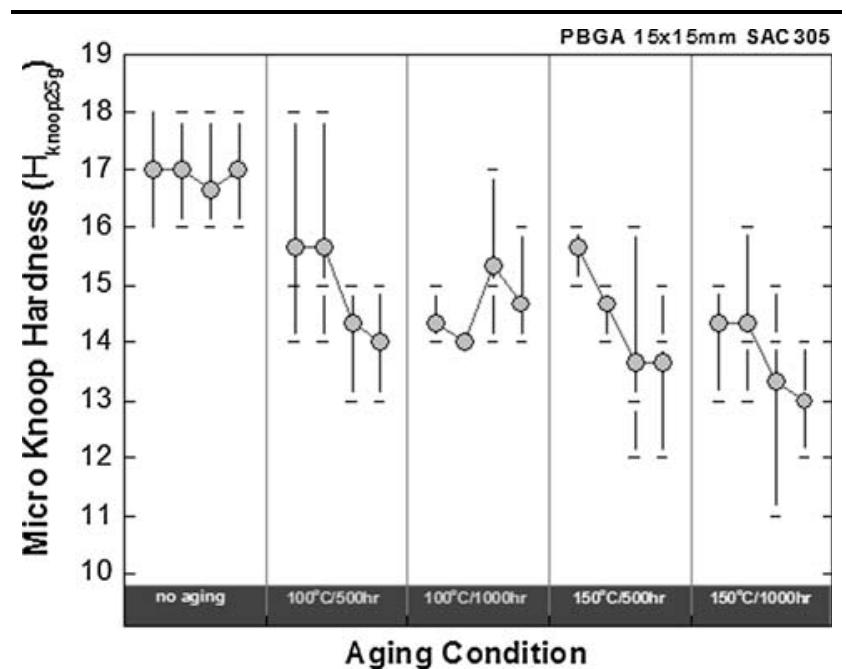

Fig. 9. Microhardness (Knoop) results for each aging condition. Four data points were taken from package side to board side (left to right) for each aging condition. useful and complete information, as shown in Fig. 11. In this example, the subgrain structure is evident in the two right-hand OIM maps, where subtle color differences reveal well-developed lowangle boundaries in the 010 map. In the map, a $7^{\circ}$ boundary within a section of the beach ball is visible.

Regarding imaging of the grain structure in solder joints, polarized-light micrographs give an approximate understanding of microstructure, but OIM has the ability to give a more complete view. It takes more time and effort to obtain a complete map, but better quantification of orientation and microstructural information is possible. Further characterization of Sn-based solder joints with OIM maps will be the topic of a future publication.

\section{CONCLUSIONS}

From a macroscopic point of view, the overall distribution of single- and multigrained solder joints is dependent on processing variables. Based on observations using polarized-light microscopy, a distribution map of single-grained solder joints shows that thermal aging has a relatively small impact on the overall fraction of single-grained

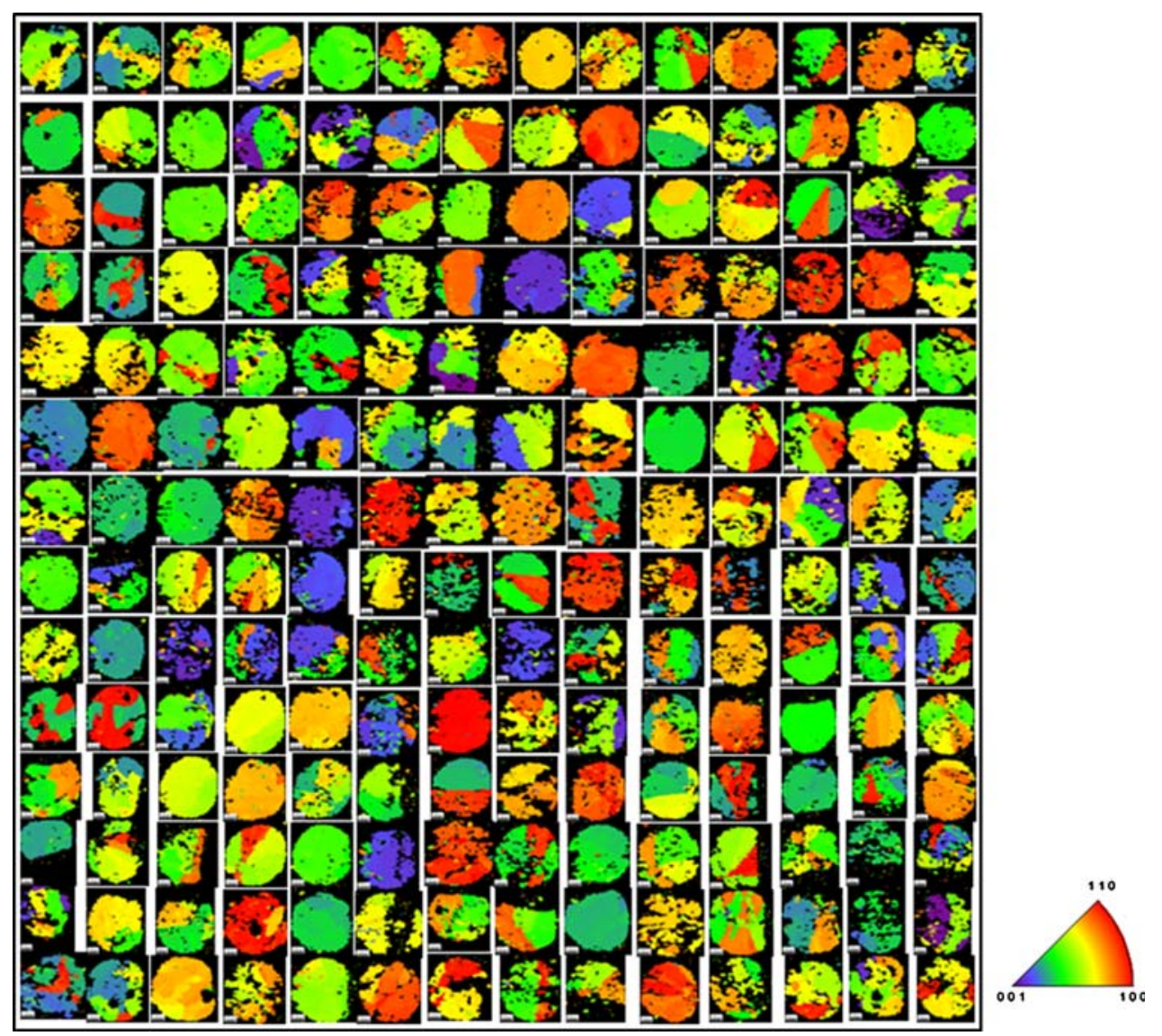

Fig. 10. OIM $c$-axis Sn grain orientation map for PL-150-t2-TC2. When the $c$-axis is parallel to the board it is red, and when it is perpendicular to the board it is blue (colored figure available in the electronic version). 

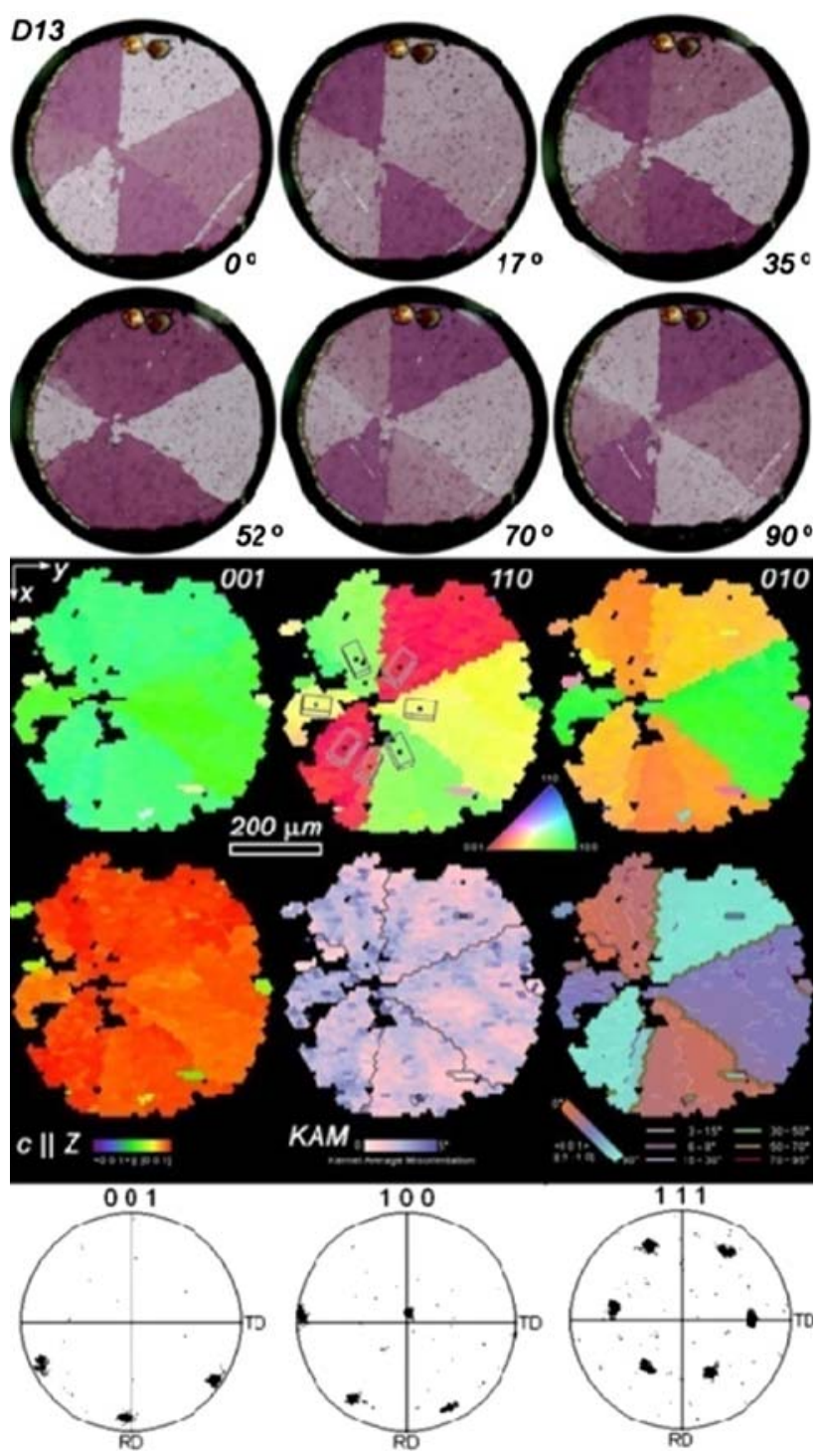

Fig. 11. Comparative imaging of ball D13 of PL-150-t2-TC2 using polarized light and OIM analysis. The polarized image depends on the specimen orientation, and many different OIM maps reveal different aspects of the microstructure (color figure available in the electronic version). solder joints, but with thermal cycling, many singlegrained joints transform to multigrained joints. A combination of thermal aging and thermal cycling further increases the fraction of multigrained joints. A change in the distribution of single- and multigrained joints is only one part of the evolution process that occurs during thermal cycling. A detailed study using polarized-light microscopy and OIM will provide further understanding of the deformation and microstructure evolution processes that occur during thermal cycling, ultimately leading to greater understanding of the effect of grain orientation on package reliability.

\section{ACKNOWLEDGEMENTS}

This work is a collaborative research project between Cisco Component Quality and Technology group and Michigan State University, funded by Cisco systems, Inc.

\section{REFERENCES}

1. D. Frear, H. Morgan, and J.H. Lau, eds., The Mechanics of Solder Alloy Interconnects (New York: Van Nostrand Reinhold, 1994)

2. J.A. Rayne and B.S. Chandrasekhar, Phys. Rev. 120, 1658 (1960).

3. B. Zhou, T.R. Bieler, A.U. Telang, T.-k. Lee, and K.-C. Liu, J. Electron. Mater., this volume (2009).

4. T.R. Bieler, H. Jiang, L.P. Lehman, T. Kirkpatrick, and E.J. Cotts, 2006 Proceedings. 56th Electronic Components \& Technology Conference (IEEE Cat. No. 06CH37766C) (2006), p. 6.

5. P. Borgesen, T. Bieler, L.P. Lehman, and E.J. Cotts, MRS Bull. 32, 360 (2007)

6. S. Park, R. Dhakal, L. Lehman, and E. Cotts, Acta Mater. 55,3253 (2007).

7. A.U. Telang, T.R. Bieler, S. Choi, and K.N. Subramanian, J. Mater. Res. 17, 2294 (2002).

8. A.U. Telang and T.R. Bieler, Scripta Mater. 52, 1027 (2005).

9. A.U. Telang, T.R. Bieler, A. Zamiri, and F. Pourboghrat, Acta Mater. 55, 2265 (2007).

10. M.A. Matin, W.P. Vellinga, and M.G.D. Geers, Mater. Sci. Eng. A 445, 73 (2007).

11. A. LaLonde, D. Emelander, J. Jeannette, C. Larson, W. Rietz, D. Swenson, and D.W. Henderson, J. Electron. Mater. 33, 1545 (2004).

12. A.U. Telang, T.R. Bieler, and M.A. Crimp, Mater. Sci. Eng. A 421, 22 (2006). 